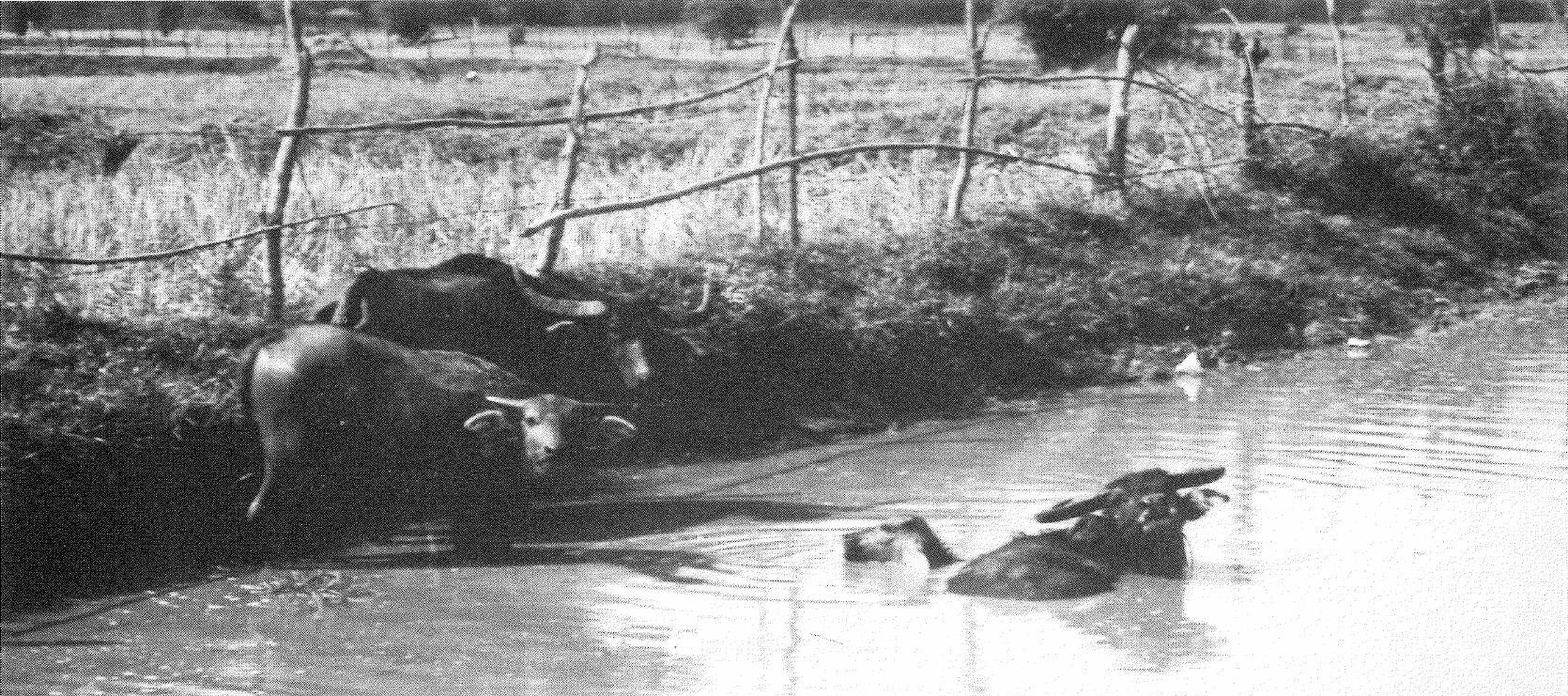

Majorie Crombie

\title{
Yritys irrottautua köyhyydestä karjankasvatusprojektin avulla
}

ICAE:n IV yleiskokous Thaimaassa jakautui ensimmäisessä vaiheessaan pieniin ryhmiin, joista kukin teki nk. solidaarisuusvierailun jonnekin påin isäntämaassa. Solidaarisuusvierailujen tarkoituksena oli tutustuttaa kansainvålisen aikuiskasvattajien kokouksen osanottajat thaikulttuuriin ja maahan erilaisten kehitysprojektien avulla. Näiden retkien - vaihtoehtoja noin 60 - merkitys oli näyttää niiitä arkipäivän ongelmia, joiden parissa kehitysmaan aikuiskasvattajat työskentelevät.

Kirjoittajan kuvaamaan retkeen osallistui hänen itsensä lisäksi 10 henkeä: kolme korealaista, yksi zimbabwelainen, yksi tansanialainen, yksi singaporelainen ja yksi macaolainen sekä konferenssin suomalaisosanottajat Timo Toiviainen, Christoffer Grönholm ja Anneli Kajanto. Kirjoittaja, lehtori Majorie Crombie Australiasta, työskentelee kotimaassaan siirtolaislasten englanninkielen alkeiden kohottamiseksi. Hänen oppilainaan on myo̊s suomalaislapsia. 
Vedenpuute on koillisthaimaalaisten kylien polttava ongelma. Alue on muinoin ollut merenpohjaa ja siksi pohjavesi on suolaista. Karja etsi helpotusta helteeseen ojista ja lammikoista. Varsinainen kuiva kausi oli vasta edessä.
Minibussimme kääntyi Bangkok - Khon Kaen päätieltä 330 kilometrin päässä Bangkokista koilliseen. Tästä soratie kiemurteli tasaisen, riisipeltoihin jakautuneen maan halki. Satunnaisesti kookospalmuja, olkihattuisia ihmisiä pellolla työssä, lehmiä ja puhveleita ympärillä. Ei koneita näkyvissä. Ei kiirettä. Viimeistä riisisatoa korjataan, oljet kerätään pinoihin ja ihmiset puivat viimeisiä riisinjyviä niistä käsin.

Tällainen rauhallisuus on taustana seuraavalle kahdelle päivälle, jotka olemme Son perheen vieraina Tha Nang Naewin kylässä.

Tietä reunustavat ojat, joissa on sadekauden viimeiset vedet. Jotkut ojat ovat täynnä kasvillisuutta ja kaloja, joita kalastetaan. Mutta monet ojat ovat tyhjiä ja auringonkuivattamia. Tällainen vedenpuute on kyläläisten polttava ongelma. Ei näy merkkejä keinokastelusta. Seuraavat sateet tulevat vasta toukokuussa. Tämä on talvea, vaikka lämpötila onkin $+30 \mathrm{C}$ ja ilmankosteus korkea. Kuuma aika tulee vielä, ennen kuin sateet tuovat helpotusta kasveille, eläimille ja laitumille.

Kyytimme pysähtyy tyypillisen thaitalon eteen kadulla, joka on täynnä tyypillisiä thaitaloja; pylväiden varaan tummasta teakpuus- ta rakennettuja. Oleskelutilat ovat ahtaat ja nukkumatilat ylhäällä. Kaduilla lehmiä, kanoja, satunnainen koira ja näillä kaikilla etuajo-oikeus. Jatkuvasti ihmisiä kulkemassa ohi rutiiniaskareissaan - kuljettamassa eläimiä, menossa ostamaan tai myymään tai keräämään tai kuljettamaan. Kulkuvälineet ovat käsikärryjä ja satunnainen moottoripyö. rä, monikäyttökuormuri tai auto.

Ihmiset tulevat joka suunnasta tervehtimään meitä. Me kaksi naista joudumme syleiltäväksi ja meidät viedään jonkin talon keittiöön. Muut häviävät jonnekin. Me olem. me kadottaneet kontaktin elämänlankaam. me, tulkkiin. Liitymme lattialla jalat ristissä istuvien naisten joukkoon. He valmistavat ateriaa. Tervehdin heitä "sawadee ka" ja "wai", johon he runsaasti ja toistuvasti vastaavat.

He puhuvat meistä ja kikattavat äänekkäästi. Alamme avata herneenpalkoja ja yritämme viestittää solidaarisuuttamme. Keskitymme työhömme yrittäen samanaikaisesti saada katsekontaktia ja hymyillä. Ponnistelen muistaakseni edes jonkin thaikielen lau. seen, mutta turhaan. Sanakirjakaan ei anna mitään apua tällaiseen äkilliseen tapaukseen. Lähes paniikissa takerrumme muihin kommunikaatioyrityksiin ylittäessämme lähes mahdottomantuntuisen muurin. Aika näyttää pysähtyneen ja nykyhetki tuntuu loputtomalta ilman pakotietä. Me kaksi vaihdamme kommentteja ja kikatamme. Ainakin olemme löytäneet keskinäisen kommunikaation.

Huomaan, että minulla on yhä kengät jalassa ja otan ne nopeasti pois. Muistan, että Thaimaassa on tabu osoittaa jaloillaan toista henkilöä ja mainitsen tästä suomalaiselle kollegalleni. Se saa hänen olonsa epämukavaksi ja hän yrittää piilottaa jalkojaan alleen. Kuinkahan paljon jo olemme pahastuttaneet isäntäväkeämme! Eräs thaimaalainen ryhmämme huoltaja tulee ja puhuttelee meitä thaikielellä. Katsomme toiveikkaan lattialta, mutta jatkamme pian taas palkojen avaamista, sillä hän ei tarjoakaan meille mitään vaihtoehtoa.

Alamme kehittää kielitaitoamme. Naiset ottavat jonkin esineen ja sanovat sen nimen thaiksi. Yritämme toistaa. Lisää sanoja seuraa. Muistan miten sanotaan "en emmärrä". Nyt alamme edistyä - kommunikoimme ja olomme tuntuu mukavammalta. Olemme 
avanneet herneenpalkoja, viikon tarvetta varten luultavasti, mutta kukaan ei puutu työhömme.

Herneenpalkovati on lähes tyhjä - aika tehdä uusi päätös. Pelastus saapuu! "Ruoka", "syödä", "tule". Seuraamme halukkaasti. Liitymme muuhun ryhmään, joka istuu talon lattialla ympärillään loputtomasti riisivateja ja astioita täynnä vihanneksia ja erilaista lihaa. Ne kaikki näyttävät vastustamattomilta ja ovat erittäin tervetulleita kahdeksantuntisen yli yön kestäneen ajomme jälkeen. Tämä on aamiainen. Rentoudun ja ajattelen, kuinka mukavaa kyläelämä on.

Jääkaapista otettuja vesipulloja kiertää. Ainoa huoli mielessäni on nyt, kuinka selviän vessajärjestelyistä. Myöhemmin totun hyvin kyykkyvessaan ja kädenpesuastioihin. Itse asiassa alan olla ylpeä siitä, kuinka siisti ja puhdas olen. Alan nauttia systeemistä ja jopa ajatella, kuinka epähygieenisempi eurooppalainen tapa on.

Syömme runsaasti ja monet kädet korjaavat astiat pois, tuovat ison pöydän ja tarpeek. si tuoleja kaikille kylän edustajien kanssa käytävää keskustelua varten. VIP:t istuvat pöydän ympärillä ja muut taustalla talo hämärässä. Tämä ateriointi/kokoustoimitus toistuu seuraavina päivinä monta kertaa.

Kokoustavat ovat täällä erilaisia. Muodollisuuksia, esittelyjä ja kohteliaisuuksia noudatetaan tarkasti. Aika ei ole tärkeää. Aloitetaan alusta ja jatketaan asteittain, kunnes jokainen saatavissa oleva ihminen on esitelty, on puhuttu, puheen yhteenveto esitetty, häntä on kiitetty jne. Katosta roikkuvan ison tuulettimen alla istuen aivan kuin vaivumme hypnoosiin tässä prosessissa. Toisella tasolla ajelehtivat ajatukset ja huomiot auttavat meitä suodattamaan toisen esityslistan; tämä on thaimaailmankuva.

Kun kokous jatkuu, kaikenikäiset kyläläiset kerääntyvät talon laajaan oviaukkoon. Isäntämme, ESA:n karjankasvatusprojektin koordinaattori, kertoo projektista ja laajasti. Hänen thainkielinen puheensa käännetään englanniksi, joka hidastaa prosessia. Vastaavasti kysymykset ja niiden vastaukset käännetään edestakaisin. Hän kertoo meille kylän köyhyydestä, veden riittämättömyydestä, ruuasta, voimavarojen vähäisyydestä, velkaantumisesta jne.
Hän on ollut avainhenkilö organisoitaessa ryhmiä parantamaan tilannetta. On tapahtunut siirtymää riisinviljelystä karjankasvatukseen, koska tämä tuo kylään enemmän tuloja ja lihan hinta on riisin hintaa vakaampi.

Uudet projektit ovat melko vaatimattomia; vain vähän karjaa, monia epäonnistuneita alkuja, joissa eläimiä on kuollut, projektit ovat romahtaneet ja ulkopuolelta tuleva apu ollut vähäistä, joskus epäsopivaa, joskus satunnaista. Hän puhuu riisipankeista, rahanlainaamisesta ja kylän erilaisista ryhmistä rikkaista "kapitalisteista" perheisiin, joilla ei ole omaa maata eikä omia lehmiä.

Hänen jälkeensä tulee kylän muita edustajia joukoittain "organisaation" eri puolilta; nuorisojohtajia, naisten ryhmiä, eläinlääkintäasiantuntijoita, opettajia ja koordinaattoreita. Status on hyvin tärkeää ja arvonimet hy. vin muodollisia. Jokaisella on tarkasti mää. rätty paikka hierarkisessa organisaatiossa, jota esitellään hyvin laajasti.

Kuitenkaan kenelläkään näistä "asiantuntijoista" ei ole paljonkaan asiantuntemusta tai koulutusta ja ideoiden- ja ajatustenvaihto heidän ja paikallisten kasvatuskeskusten kanssa on minimaalista. Ns. eläinlääkäri on käynyt neljä luokkaa koulua ja sen jälkeen lyhyen kurssin, jossa opettajina on ollut toisia samanlaisia "lääkäreitä". Koko organisaatio on perustettu ylevien poliittisten ideoiden pohjalle nostamaan tietoisuutta ja kohottamaan paikallisten asukkaiden osallistumista. Tätä rakennetta esitellään ja selitetään monilla kaavakuvilla.

On muutamia menestystarinoita, mutta tiukan muodollisen organisatorisen rakenteen ja muodollisten kokousten takana näyttää olevan aika paljon tiedon, asiantuntemuksen ja resurssien puutetta, jotta kovinkaan paljon edistystä voisi tapahtua. Kerääntynyt vähä kokemus on jaettu muidenkin ky. lien käyttöön ja 17 kylän koordinaattori on ihailtavan urhea, nuori ja kunnioitusta osak. seen saava henkilö.

Son, isäntämme ja projektin johtaja suhtautuu torjuen ajatukseen, että ulkoa tulevat asiantuntijat veisivät aloitteen kyläläisiltä. Ja vaikka tämä olikin meistä oikeantuntuinen asenne, tuntui samalla, että ilman ulkopuolista apua voisi tapahtua vain vähäisen edistystä. 
Noin viiden tunnin kuluttua olimme kuulleet kaiken äänen. Kaikki esitykset olivat hyvin muodollisia ja tämän seikan sekä käännöksen aiheuttaman vaikeuden vuoksi oli vaikeaa päästä pintaa syvemmälle. Oli vaikeaa saada kuvaa suhteista ulkopuolisiin organisaatioihin, rahoitustilanteeseen, projektien käyttöön jne. Oli vaikeaa päätellä, mikä oli suurin este kommunikaatiolle; puolustelu, "kasvojen pelastaminen", sen kertominen mitä meidän oletettiin haluavan kuulla, thailainen tapa tehdä asioita jne. Näimme vain muutamia yrityksiä uusista tavoista, kokeiluista.

Iltapäivällä kävelimme kylässä. Näimme vanhoja naisia useissa taloissa silkinvalmistuksen eri vaiheissa - toukkien kasvatuksessa, kotiloiden keräämisessä, kehräämässä silkkilankaa ja kutomassa siitä monimutkaisia kuvioita. Monilla heillä oli yllään käsikutoisia, käsintehtyjä silkkipuseroita ja hameita. Useimmat työntekijät olivat hyvin vanhoja. Jotkut hoitivat pieniä lapsia.

Kylässä näytti nuorten ihmisten keskuudessa olevan hyvin vähän kiinnostusta vanhoihin ja perinteisiin rooleihin ja käsitöihin. Näytti siltä, että tämä hauras elämäntapa kuolisi, jollei nuoria saataisi enemmän mukaan. Tietenkin nuoriso oli koulussa, mutta heidän kiinnostuksensa on enemmän länsimaisissa päämäärissä. Perinteisen elämäntavan säilyttämiseen ei ole paljonkaan motivaatiota. Ja Bangkokia houkutuksineen ei voi jättää huomiotta. Länsimainen murrosikäisen ikävystyneisyys näyttää tunkevan läpi.

Kävimme kansa- ja keskikoulussa, joissa oppilaat näyttivät puuhaavan tyytyväisinä hy. vinkin akateemisesti opetettavassa ulkoluvussa ja kopioivan siistillä käsialalla vihkoihinsa. Amerikkalainen vapaaehtoinen (Peace Corps) opetti englantia, mutta oppilaat pitivät sitä kuolleena kielenä. Opetustapa oli hyvin kielioppikeskeinen ja kiinnostus aiheeseen varsin laimea. Mutta oppilaat tervehtivät meitä hymyilevin thaikasvoin iloisesti.

Näytti siltä, että kylässä on ruokaa runsaasti: kalaa, hedelmiä ja monenlaista lihaa kanoista ja vuohista lehmiin. Vähäosaisilla kylän laitamilla oli vain välttämättömin eikä toivoa enemmästä.
Illalla näimme toisenlaista rikkautta kulttuuria, kylän yhteisöllistä elämää. Siestan jälkeen ja tietenkin yhden lisäjuhlan jälkeen, jossa tarjottiin riisiviiniä likaisin sormin käsitellyistä laseista ja muista astioista, pääkatu alkoi peittyä mattoihin ja kansaa kerääntyä paikalle. Mikrofoneja ja kovaäänisiä aseteltiin paikoilleen ja thai- sekä laoslainen musiikki kajahti ilmoille. VIP-vieraat saavat perinteisen vastaanoton ja siunauksen.

Kylän miehet löivät rumpujaan soinnilliseen rytmiin. Me 11 vierasta istuimme ympyrässä, koristellun kultaisen astian ympärillä, joka oli täytetty banaaninlehdillä ja koristeltu hyväntuoksuisilla kukkaseppeleillä. Siinä oli myös lyhyistä puuvillalangoista tehtyjä kimppuja, joiden merkitys selvisi meille myöhemmin.

Joku kylän vanhimmista lauloi, kun meitä siunattiin buddhalaisin menoin, toivotettiin tervetulleiksi ja jokaiselle asetettiin kukkaseppele kaulaan. Sen jälkeen käännyimme ympyrässämme kohti useiden satojen kyläläisten joukkoa. Ihmiset tulivat luoksemme ja sitoivat noita puuvillalankoja ranteisiim. me laulaen samalla hyvän onnen toivotuksia. Vaihdoimme tervehdyksiä "wai" ja "Khawp khun ka". Se oli hyvin korutonta. Jokainen osallistui seremoniaan, niin vanhat kuin nuoretkin. Niinpä meillä jokaisella oli puuvillalan. koja ranteissamme kimputtain, sidottuna päättäväisyydellä - tapa, joka on säilynyt muuttumattomana sukupolvesta toiseen. Meille tämän tradition kohtaaminen oli hyvin vaikuttava kokemus. Kommunikaatiota sanojen keinoin ei tarvittu.

Rituaalin jälkeen istuimme sivummalle ja seurasimme perinteisiin asuihin pukeutuneiden tanssijoiden esityksiä - kylän nuoret tytöt ja pojat esittivät kauniita tansseja kuvaten vanhoja tarinoita ja toiveita. Puvut olivat kirkkaanvärisiä, pojilla oli voimakkaasti maalatut kasvot ja liikkeet olivat täsmällisiä ja hyvin rytmikkäitä. Tanssijoilla oli mukanaan koreja, kalaverkkoja jne. Kyläläiset heittelivät heille kolikoita.

Vanhat miehet rummuttivat rytmejään ja lauloivat joitakin vanhoja lauluja. Traditionaa. liset thaitanssit jatkuivat. Lopulta, koska olimme saaneet jo niin paljon, oli meidän vuoromme antaa. Tässä vaiheessa minä englantilaisaustralialaisena olin hyvin nöyrä havaitsessani oman melko köyhän kulttuuriperinteeni. Korealaisia ja armenialaisia (amerikkalainen vapaaehtoistyöntekijä oli armeni- 
alaista sukujuurta) rakkauslauluja esitettiin ja kyläläiset tottuivat nopeasti rytmiin rummuttaen ja tanssien spontaanisti. Miten he osallistuisivat australialaiseen kansanlauluun "Tanssi Matilda"? Tästä velvoitteesta en pääsisi pakoon, mutta polkka pelasti minut. Tempasin parin itselleni, hyppäsin rytmiin ja aloin työnnellä suomalaista melko äkillisin askelin. Paniikissa unohdin askelkuvioita, mutta onnistuimme samaan aikaan jotakin, jota toistimme muutaman kerran ja saimme kyläläiset liittymään mukaan. Rummuttajiakin liittyi mukaan. Tanssi meni hyvin ja katsoimme meidän vieraiden jo täyttäneen esiintymisvaatimuksen. Kättentaputuksia ja huutoja ja sitten siirryttiin thaitanssiin.

Ilta oli todellakin kaunis siinä kadulla lämpötilan laskiessa ja kevyen tuulen noustessa. Riisiviini virtasi ja vaikeaa oli olla tanssimatta. Sopivalla ajalla VIP:t lähtivät pois ja laulu ja rummutuskin vaikenivat hetken kuluttua.
Siirryimme yläkertaan nukkumaan mukavasti lattialle, jota peittivät matot, paksut patjat ja tyynyt. Moskiittoverkotkit olivat saatavilla.

Aamulla heräsimme auringon noustessa, kukkojen rääkyessä ja kaksitahtimoottoreitten alkaessa räpätyksensä. Lehmänajajat veivät karjaa kyläkatua myöten riisipeltojen taakse. Toimitus oli hidas ja rauhallinen. Maailma näytti hyvältä ja kaikella oli paikkansa.

Uutena päivänä jatkui lähikylissä vierailut: tervehdykset, siunaukset, selostukset nuorten toiminnasta, naisten ryhmistä, lehmistä, veloista jne. Totuimme siihen ja asioiden rauhalliseen tapahtumisvauhtiin. Kello unohtui ja jatkoimme vaihe vaiheelta kokemuksia, joita vastaamme tuli. Osasimme korealaisen rakkauslaulun jo ulkoa ja esitimme sitä auliis-

Satamåårin kylålåisiä kokoontui auringon laskettua kylän keskustaan, misså katu oli katettu olkimatoin illan juhlan kunniaksi. Juhla alkoi buddhalaisella rituaalilla, jossa saimme siunauksen. 96 prosenttia thaimaalaisista on buddhalaisia.

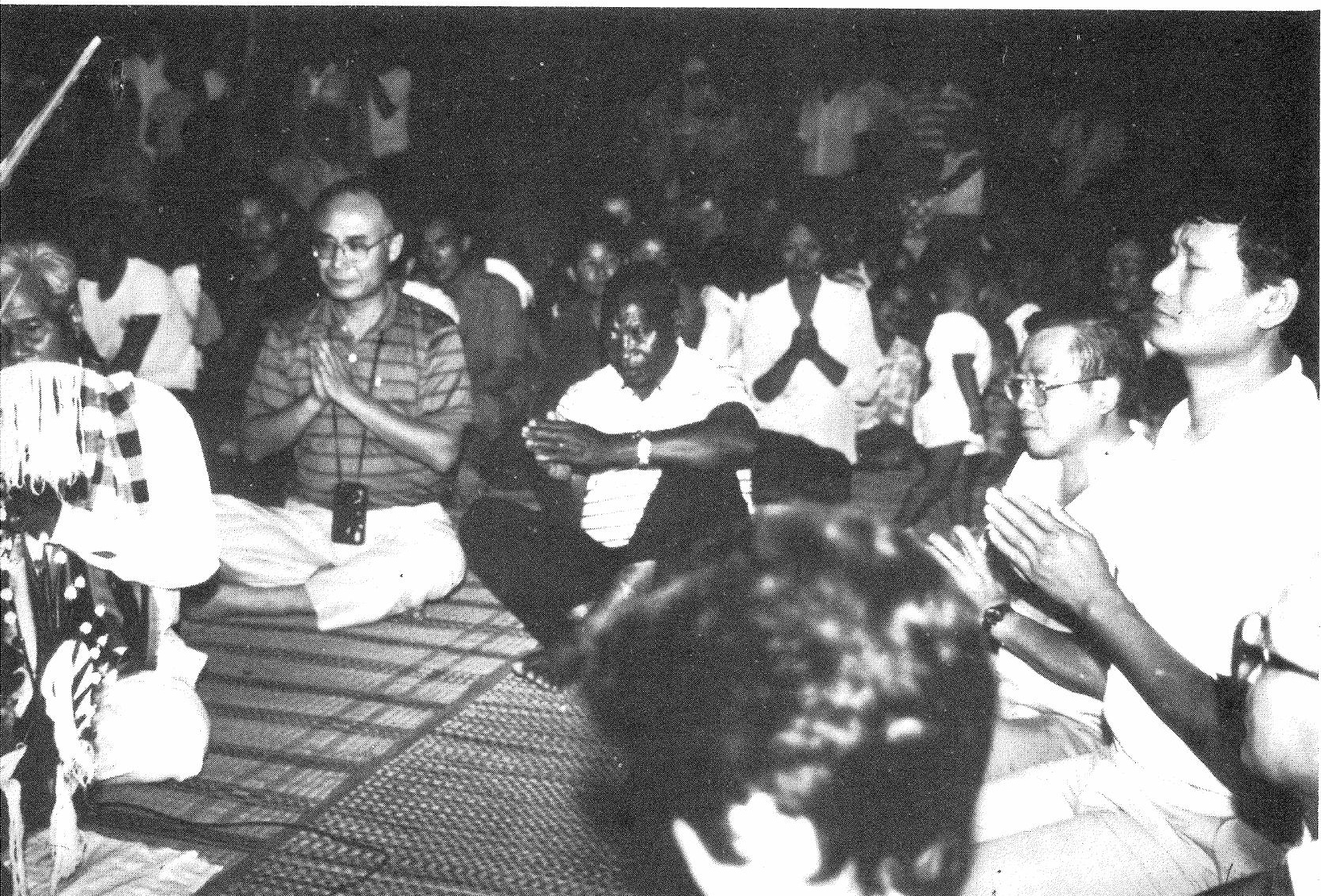




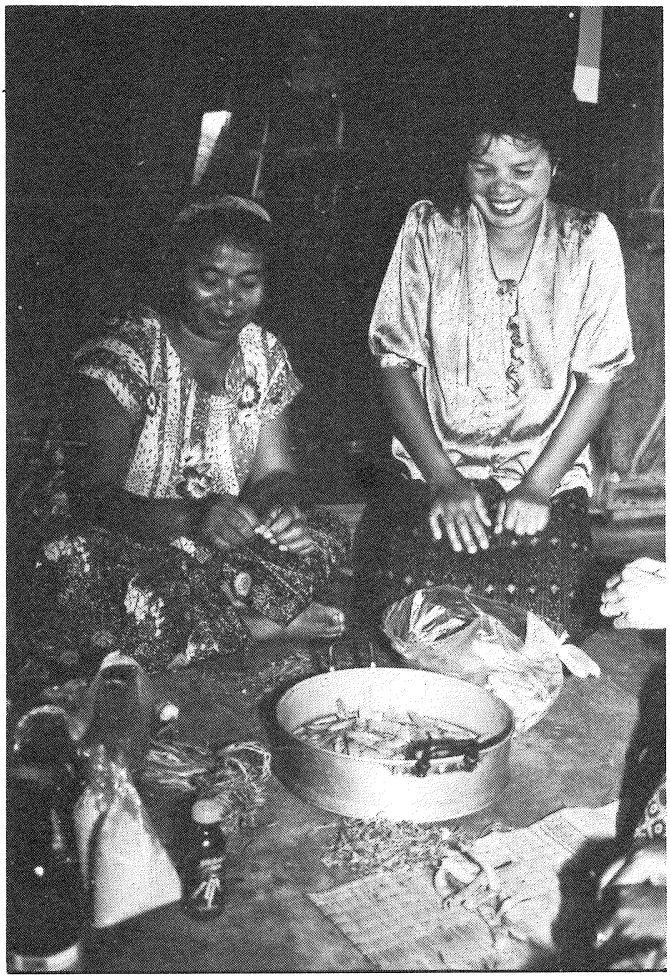

Ajankäsite on tyystin toinen kuin se, mihin länsimainen ihminen on itsensä sitonut. Ruuanvalmistukseen permannolla osallistui melkoinen joukko naisia. Ruuanvalmistuksen eri käsityövaiheet ovat työteliäitä ja työ tehdään suurella pieteetillä. ti. Joka kerta kyläläiset yhtyivät kättentaputuksilla ja tanssilla mukaan. Erityisesti vanhat naiset eivät olleet unohtaneet rytmitajuaan.

Viimeisessä kylässä meiltä ensi kertaa kysyttiin, mitä mieltä olimme heidän ongelmistaan ja mitä me voisimme esittää niiden ratkaisemiseksi. Aikuiskasvattajamme Zimbabwesta, Tansaniasta, Koreasta jne. jakoivat kokemuksiaan samantapaisista tilanteista omissa maissaan. Sitten esitettiin toivomus, että jompi kumpi vierailevista naisista puhuisi jotakin. Keräsin rohkeuteni ja kerroin mitä sillä hetkellä tunsin: kyläläisten rikkaasta kulttuurista, kiinteistä perhesuhteista, perinteistä. Puhuin vaarasta, joka saattaa uhata kaiken tämän menettämisessä, kun kuljetaan kohti kulutusyhteiskuntaa. Toivoin, että he rakentaisivat kehitystään tämän rikkautensa varassa.

Yritin kertoa heille Australian alkuperäiskansoista ja siitä, kuinka pettyneitä he ovat kaupunkielämään ja kuinka he pyrkivät palaamaan takaisin juurilleen aloittaakseen uudelleen harmoonisen elämäntavan.

Olimme valmiit siirtymään eteenpäin ohjelmassa, viimeiseen ateriaan. Tällä kertaa oli kasoittain tuoretta papaijaa ja kookospähkinöitä, joissa oli olki valmiina kookosmaidon imemistä varten - ja viimeisenä thaihierontaa niille, jotka sitä halusivat.

Bangkokin kampuksella otin pitkän suihkun ja vaihdoin vaatteet. Tuntui hyvältä. Ehkä tällaisessa elämässä on hyvät puolensakin. Mutta en tuntenut, että tarvittaisiin juurikaan hotellin tarjoamia päivällisiä ja sen steriloituja, muoviin käärittyjä laseja.

\section{KIRJALLISUUTTA}

Thaimaalaisen kylän rakennetta, historiaa ja murrosta käsittelee Martti Sarmelan tutkimus Paikalliskulttuurin rakennemuutos, Raportti Pohjois-Thaimaan riisikylistä, Suomalaisen Kirjallisuuden Seura ja Suomen Antropologinen Seura 1979, II Iyhennetty painos (1988) 329 sivua.

Thaimaan prostituution juuria toisen maailmansodan jälkeiseen maatalouspolitiikkaan käsittelee Aila Auvisen, Tuula Minkkisen ja Helvi Saarisen raportti Prostituutio ja seksiturismi, Unioni Naisasialiitto Suomessa ry. 1986. 